\title{
Examining the Psychometric Properties and Clinical Correlates of the Korean Version of the Family Accommodation Scale-Self-Rated Version for Obsessive-Compulsive Disorder
}

\author{
Jhin Goo Chang', Hye Min Lee', Se Joo Kim²,3, and Chan-Hyung Kim ${ }^{2,3}$ \\ 1'Department of Psychiatry, Myongji Hospital, Hanyang University College of Medicine, Goyang, Republic of Korea \\ ${ }^{2}$ Institute of Behavioral Science in Medicine, Yonsei University College of Medicine, Seoul, Republic of Korea \\ ${ }^{3}$ Department of Psychiatry, Yonsei University College of Medicine, Seoul, Republic of Korea
}

Objective We aimed to develop a Korean version of the Family Accommodation Scale-Self-Rated (FAS-SR), to investigate its reliability and validity and to study the clinical correlates of family accommodation in families with obsessive compulsive disorder (OCD) patient. Methods The FAS-SR was translated into Korean under the original author's supervision. Forty-two patients with OCD and their closest relatives participated. The internal consistency was estimated using Cronbach's alpha and the split half method. Convergent and divergent validity were identified by measuring with other clinical variables. Test-retest reliability was also calculated.

Results The reliability analyses showed that Korean version of the FAS-SR demonstrated excellent internal consistency (Cronbach's alpha $=0.91$ ) and test-retest reliability (Intraclass correlation coefficient=0.93). It showed good convergent validity when simultaneously assessed OCD symptom severity, global functioning and relative's psychological distress.

Conclusion The findings suggest that Korean version of the FAS-SR is a reliable and valid tool for assessing family accommodation in Korean patients with OCD in both research and clinical settings.

Psychiatry Investig 2022;19(3):207-212

Keywords Obsessive-compulsive disorder; Family accommodation scale; Korean version.

\section{INTRODUCTION}

Obsessive-compulsive disorder (OCD) is a chronic disorder characterized by unwanted repetitive thoughts (obsessions) and/or behaviors (compulsion), ${ }^{1}$ affecting approximately $1 \%-$ $3 \%$ of the adult population. ${ }^{2,3}$ Obsessive-compulsive symptoms are highly distressing and hard to ignore, worsening the quality of life of patients. ${ }^{4-6}$ OCD patients experience significant interference in various aspects of their lives, including social, occupational impairment. ${ }^{7,8}$ Families of OCD patients also experience higher distress, compared with families with other psychiatric illnesses patients, since OCD symptoms are often related to or dependent on family members. ${ }^{9,10}$

\footnotetext{
Received: October 18, 2021 Revised: November 29, 2021 Accepted: December 6, 2021

$\triangle$ Correspondence: Chan-Hyung Kim, MD, PhD

Department of Psychiatry, Severance Hospital, Yonsei University College of Medicine, 50-1 Yonsei-ro, Seodaemun-gu, Seoul 03722, Republic of Korea Tel: +82-2-2228-1620, Fax: +82-2-313-0891, E-mail: spr88@yuhs.ac

(a) This is an Open Access article distributed under the terms of the Creative Commons Attribution Non-Commercial License (https://creativecommons.org/licenses/bync/4.0) which permits unrestricted non-commercial use, distribution, and reproduction in any medium, provided the original work is properly cited.
}

Family accommodation (FA) refers to a phenomenon in which family members adjust their lifestyle according to the patient's obsessive-compulsive symptoms. In particular, family members often participate in the patients' rituals or modify their routines to avoid triggering the patients' symptoms. ${ }^{11} \mathrm{FA}$ is highly prevalent in families of patients with OCD, with up to $97 \%$ of family members reporting that they accommodate symptoms in a significant way. ${ }^{12,13}$ Although, it may temporarily relieve a patient's anxiety, paradoxically, it contributes to destroying the family's quality of life $^{14}$ and reducing the effectiveness of the patient's treatment by preventing them from exposure to obsession. ${ }^{13,15}$

Growing body of researches focus on clinical correlates with family accommodation. For example, higher symptom severity, lower general functioning and specific OCD symptom dimensions (such as cleaning and comorbid mood symptoms) were associated with higher family accommodation. ${ }^{16-19} \mathrm{Re}-$ garding relatives' factors, higher family conflict, familial aggression, and feelings of anger and anxiety demonstrate higher family accommodation. ${ }^{19}$ However, most of researches have been carried out in American and Western-European societies, and 
there has been a lack of cross-cultural studies examining family accommodation in OCD family.

The interviewer-rated Family Accommodation Scale for Obsessive-compulsive Disorder (FAS-IR), an instrument that assesses 12 accommodating behaviors, has been considered the gold standard for assessing the types and severity of FA. ${ }^{11}$ However, FAS-IR has some disadvantage using in clinical practice because significant time spent in interviewer training/administrating. Further, it may miss some accommodating behaviors, as family members may feel less willing to disclose the patient's OCD symptoms when asked directly by a clinician. ${ }^{20}$ The selfrated version of the Family Accommodation Scale for Obsessive-compulsive Disorder (FAS-SR) is a modified version of the FAS-IR to compensate for the latter's shortcomings by Pinto et al. ${ }^{16}$ The FAS-SR is a self-report measure assessing accommodating behaviors in the past week, completed by the relatives of patients with OCD. The FAS-SR has already been translated in Japan and India and demonstrated excellent internal consistency and good convergent validity with related constructs (e.g., OCD symptom severity, overall psychosocial functioning, family functioning, and distress experienced by patients' relatives). ${ }^{21,22}$ Thus, the FAS-SR can be considered a practical alternative to the FAS-IR and has sufficient potential to be widely applied. ${ }^{13}$

Patterns of caregiving and beliefs about disease vary widely across cultures and could lead to substantially different responses to patients' obsessive-compulsive symptoms. ${ }^{23}$ In Korea, to the best of authors' knowledge, there exists no tools assessing FA in OCD family. Therefore, this study aimed to standardize the Korean version of the FAS-SR and explore the characteristics of family accommodation behavior in Korea.

\section{METHODS}

\section{Development of the Korean version of the FAS-SR}

With the original author's permission, the FAS-SR was translated into Korean this paper's first author. Back-translation into English was performed by a bilingual translator with a medical background who was familiar with the original FAS-SR. The back-translated version was sent to Dr. Calvocoressi, one of the developers of the original FAS-SR. The first author then revised the Korean translation according to the feedback received. After repeating this procedure, the equivalence of the original version and Korean version of the FAS-SR was confirmed.

\section{Participants and procedures}

All participants and their relatives gave their informed written consent after the study procedure was fully described to them. This study was approved by the Severance Clinical Review Committee (2017-3250-001). We enrolled OCD patients who could read and respond to the questionnaires, as well as understand the explanations of the researcher or assistant researcher. Participants were individuals aged over 19 years who met the DSM-5 criteria for OCD. They were recruited from the Severance Hospital between May 2018 and January 2021. We defined relatives as individuals who routinely lived with patients and/or had substantial contact with them. Participating relatives were those who reported that they were most intimately involved in caring for the patient with OCD. The study participants included 42 outpatients and 42 relatives. We asked 12 relatives to complete the FAS-SR again within 1 month after we received all questionnaires.

\section{Measures administered only to patients}

\section{The Global Assessment of Functioning Scale (GAF)}

The Global Assessment of Functioning Scale (GAF) is a single interviewer's assessment, scored from 1 to 100 , that is used to examine the overall severity of psychopathology and dysfunction in the worst week of the past month. Higher scores indicating better overall adjustment and higher functionality.

\section{Measures administered only to relatives}

\section{Korean version of the Family Accommodation Scale for OCD-Self-Rated}

The FAS-SR is a 19-item self-rated questionnaire that measures the level of family accommodation in response to obsessive-compulsive symptoms. According to the first section of the original FAS-SR, relatives were initially asked to identify the patient's current OCD symptoms based on a modified YaleBrown Obsessive-Compulsive Scale (Y-BOCS-SC) symptom checklist. In the second section, relatives were asked to assess the frequency of 19 accommodation behaviors using a 5-point Likert scale ranging from 0 (never) to 4 (every day). The original version of the FAS-SR has excellent internal consistency (Cronbach's alpha $=0.90$ ) as well as good convergent and discriminant validity. ${ }^{13}$

\section{Family Assessment Device (FAD) ${ }^{24}$}

The Family Assessment Device (FAD) is a self-reported list of 60 items for assessing family functioning using a 4-point Likert scale ranging from 1 (strongly agree) to 4 (strongly disagree). Based on the McMaster Model of Family Functioning, the FAD measures six dimensions: affective involvement, affective responsiveness, behavioral control, communication, problem-solving, and role. The FAD also measures general family functioning. We used the validated Korean version of the FAD to examine the convergent validity of Korean version of the FAS-SR. ${ }^{25}$ Of the original 60 questions, 51 were used in this 
study, excluding nine questions with low correlation. A higher score indicates more effective family functioning. The Cronbach's alpha of the Korean version of the FAD was between 0.74 and 0.92 for each subdimension at the time of the tool development; in this study, its reliability ranged from 0.77 to 0.84 .

\section{Measures administered to both patients and relatives}

The Yale-Brown Obsessive-Compulsive Scale (Y-BOCS) ${ }^{26}$

The Yale-Brown Obsessive-Compulsive Scale (Y-BOCS) assesses the severity of OCD symptoms through semi-structured interviews. It consists of two parts: the Y-BOCS symptom checklist (Y-BOCS-SC) and the Y-BOCS symptom severity scale (Y-BOCS-SS). The Y-BOCS-SS consists of 10 items that assess the severity of obsessions and compulsions using a 5-point Likert scale ranging from 0 (no symptoms) to 4 (extremely severe symptoms), resulting in a total score ranging from 0 to 40. Within the total Y-BOCS score range of severity, 0-7 is considered "asymptomatic," 8-15 "mild," 16-23 "moderate," 24-31 "severe," and 32-40 "extreme." We used the validated Korean self-report version of the Y-BOCS-SS ${ }^{27}$ to assess the severity of patients' compulsion symptoms. The alphas for the Korean self-report version ranged from 0.69 to 0.91 . In the relative assessment, we used five items regarding compulsions from the Y-BOCS-SS to examine the convergent validity of the Korean version of the FAS-SR.

\section{Kessler Psychological Distress Scale (K6) ${ }^{28}$}

The Kessler Psychological Distress Scale (K6) is a 5-item selfreport screening scale for psychological distress using a 5-point Likert scale ranging from 1 (not at all) to 5 (always). A higher score indicates lower psychological distress. We used the validated Korean version of the $\mathrm{K} 6^{29}$ The reliability coefficient was 0.91, indicating excellent internal consistency.

\section{Barratt Impulsivity Scale II (BIS II) ${ }^{30}$}

The Barratt Impulsivity Scale II (BIS II) is a 30-item self-report inventory that assesses the personality/behavioral construct of impulsiveness using a 4-point Likert scale ranging from 1 (never) to 4 (always). We used the validated Korean version of the BIS II to examine the divergent validity of the Korean version of the FAS-SR. Its Cronbach's alpha of 0.90 indicated it had good internal consistency. ${ }^{31}$

\section{Analysis}

Descriptive statistics were obtained for clinical and sociodemographic variables. Cronbach's alpha was used to estimate the internal consistency of the Korean version of the FAS-SR. The Spearman-Brown coefficient and the Guttman split-half coefficient were used to assess the instrument's split-half reli- ability. For test-retest reliability, the intra-class correlation coefficient (ICC) was calculated. The correlation coefficient between the FAS-SR and both patient and relative-rated Y-BOCS, $\mathrm{FAD}$, and patient-rated GAF were calculated to identify the convergent and divergent validity. Correlations above 0.8 , between 0.6 and 0.8 , between 0.4 and 0.6 , between 0.2 and 0.4 , and below 0.2 were considered very strong, strong, moderate, weak, and very weak, respectively. All statistical analyses were performed using SPSS version 23 software (IBM Corp., Armonk, NY, USA).

\section{RESULTS}

\section{Sample characteristics}

The demographic profiles of the OCD patients and their relatives are shown in Table 1. A total of 42 OCD patients and their 42 relatives were included in this study. The mean YBOCS total score was 21.17 ( $\mathrm{SD}=7.46$ ), indicating moderate OCD symptom severity. Patients of varying symptom severity participated relatively evenly in this study (13 mild cases, 14 moderate cases, and 15 severe to extreme cases). $78 \%$ ( $n=33$ ) of the participating relatives were related to patients as parents.

Regarding the obsession symptom category in the FAS-SR, contamination $(50.00 \%)$ was the most common, followed by religious (42.85\%) and hoarding symptoms (35.71\%); in the compulsion symptom category, cleaning/washing (54.76\%) was the most prevalent, followed by repeating (42.85\%), miscellaneous $(42.85 \%)$, and checking (35.71\%).

\section{Frequency of each type of family accommodation}

The frequency data for the Korean version of the FAS-SR are presented in Table 2 . The most frequently reported accommodation items were Item 13 ("I did not do anything that could trigger the patient's obsessive thoughts or compulsive behavior")

Table 1. Clinical demographics of OCD patients and their relatives

\begin{tabular}{lc}
\hline \multicolumn{1}{c}{ Variables } & Mean (SD)/N (\%) \\
\hline Patients & $30.17(8.85)$ \\
Age (years) & $29(69)$ \\
Sex (male), N & $8(81)$ \\
Marital status (married), N & $9.63(6.17)$ \\
Duration of illness (years) & $21.17(7.46)$ \\
YBOCS & \\
Relatives & $54.40(9.47)$ \\
Age (years) & $33(78.57)$ \\
Relationships (parents), N & $8(19.04)$ \\
Relationships (spouses/partner), N & $1(2.38)$ \\
Relationships (siblings), N & \\
\hline OCD, Obsessive-Compulsive Disorder; YBOCS, Yale-Brown Ob- \\
sessive Compulsive Scale; SD, standard deviation
\end{tabular}


Table 2. Frequency of types and reliability data for the Korean version of the FAS-SR $(N=42)$

\begin{tabular}{|c|c|c|c|c|c|c|c|c|}
\hline & FAS-SR item & Mean (SD) & $\begin{array}{c}\text { Item } \\
\text {-total } \\
\mathrm{r}\end{array}$ & Never & $\begin{array}{c}1 \\
\text { day (1) } \\
\mathrm{N}(\%)\end{array}$ & $\begin{array}{c}2-3 \\
\text { days }(2) \\
\mathrm{N}(\%)\end{array}$ & $\begin{array}{c}4-6 \\
\text { days (3) } \\
N(\%)\end{array}$ & $\begin{array}{c}\begin{array}{c}\text { Every } \\
\text { day (4) }\end{array} \\
\mathrm{N}(\%)\end{array}$ \\
\hline 1 & Reassured patient that there were no grounds for OCD concern & $1.80(1.36)$ & 0.54 & $12(28.6)$ & $4(9.5)$ & $13(31.0)$ & $8(19.1)$ & $5(11.9)$ \\
\hline 2 & Reassured patient that compulsions took care of OCD concern & $1.62(1.27)$ & 0.51 & $11(26.2)$ & $7(16.7)$ & $15(35.7)$ & $5(11.9)$ & $4(9.5)$ \\
\hline 3 & Waited for patient & $2.26(1.81)$ & 0.87 & $13(31.0)$ & $5(11.9)$ & $1(2.4)$ & $4(9.5)$ & $19(45.2)$ \\
\hline 4 & Directly participated in compulsions & $1.62(1.68)$ & 0.54 & $19(45.2)$ & $4(9.5)$ & $1(2.4)$ & $10(23.8)$ & $8(19.1)$ \\
\hline 5 & Made it possible for patient to do compulsions & $1.07(1.39)$ & 0.43 & $22(52.4)$ & $8(19.1)$ & $4(9.5)$ & $4(9.5)$ & $4(9.5)$ \\
\hline 6 & Provided items needed to do compulsions & $1.29(1.52)$ & 0.63 & $18(42.9)$ & $12(28.6)$ & $1(2.4)$ & $4(9.5)$ & $7(16.7)$ \\
\hline 7 & Made it possible for patient to avoid OCD triggers & $1.07(1.42)$ & 0.66 & $23(54.8)$ & $6(14.3)$ & $4(9.5)$ & $5(11.9)$ & $4(9.5)$ \\
\hline 8 & Helped patient make simple decisions & $1.59(1.57)$ & 0.45 & $17(40.5)$ & $4(9.5)$ & $11(26.2)$ & $1(2.4)$ & $9(21.4)$ \\
\hline 9 & Helped patient with personal tasks (self-care) & $1.00(1.21)$ & 0.48 & $19(45.2)$ & $12(28.6)$ & $6(14.3)$ & $2(4.8)$ & $3(7.1)$ \\
\hline 10 & Helped patient prepare food & $1.17(1.71)$ & 0.34 & $26(61.9)$ & $4(9.5)$ & $1(2.4)$ & $1(2.4)$ & $10(23.8)$ \\
\hline 11 & Took on patient's family or household responsibilities & $1.36(1.51)$ & 0.52 & $18(42.9)$ & $9(21.4)$ & $3(7.1)$ & $6(14.3)$ & $6(14.3)$ \\
\hline 12 & Avoided talking about OCD triggers & $1.86(1.39)$ & 0.57 & $11(26.2)$ & $5(11.9)$ & $10(23.8)$ & $11(26.2)$ & $5(11.9)$ \\
\hline 13 & Stopped self from doing things that could trigger OCD & $2.17(1.48)$ & 0.69 & $8(19.1)$ & $6(14.3)$ & $9(21.4)$ & $7(16.7)$ & $11(26.2)$ \\
\hline 14 & Made excuses or lied for patient to cover up OCD & $0.39(0.83)$ & 0.38 & $31(73.8)$ & $9(21.4)$ & $0(0.0)$ & $1(2.3)$ & $1(2.4)$ \\
\hline 15 & Didn’t stop unusual OCD-related behaviors & $2.40(1.64)$ & 0.86 & $9(21.4)$ & $5(11.9)$ & $6(14.3)$ & $4(9.5)$ & $18(42.9)$ \\
\hline 16 & Put up with unusual conditions in home due to OCD & $1.26(1.40)$ & 0.52 & $15(35.7)$ & $15(35.7)$ & $5(11.9)$ & $0(0.0)$ & $7(16.7)$ \\
\hline 17 & Cut back on leisure time & $1.79(1.63)$ & 0.33 & $17(40.5)$ & $1(2.4)$ & $6(14.3)$ & $10(23.8)$ & $8(19.1)$ \\
\hline 18 & Changed my work/school schedule & $0.67(0.95)$ & 0.30 & $24(57.1)$ & $12(28.6)$ & $2(4.8)$ & $4(9.5)$ & $0(0.0)$ \\
\hline 19 & Put off my own family responsibilities & $0.64(1.06)$ & 0.48 & $27(64.3)$ & $8(19.1)$ & $3(7.1)$ & $3(7.1)$ & $1(2.4)$ \\
\hline
\end{tabular}

FAS-SR, the Family Accommodation Scale-Self-Rated version; OCD, Obsessive Compulsive Disorder

(79.0\%), item 15, I didn't do anything to stop unusual OCDrelated behaviors by my relative. The least common form of accommodation was "When the patient was absent from work or socially unable to live due to obsessive-compulsive symptoms, I made up excuses or lied for him/her" (27.9\%), "I put off my household chores because of the patient's obsessive-compulsive symptoms" (37.2\%).

\section{Reliability}

The item-total correlations are presented in Table 2. The overall Cronbach's alpha of the Korean version of the FAS-SR was 0.91 , indicating good internal consistency. The Spearman-Brown coefficient was 0.84 , and Guttmann's split-half coefficient was 0.83 indicating acceptable spilt-half reliability. The test-retest correlation coefficient was 0.93 ( $<<0.01$ ), indicating that the ICC for each of the 19 items of the Korean version of the FASSR was good.

\section{Convergent/divergent validity}

Table 3 shows the convergent and divergent validity of the Korean version of the FAS-SR. For convergent validity, the FAS-SR was moderately correlated with the symptom severity (Y-BOCS, $\mathrm{r}=0.64, \mathrm{p}<0.05$ ), patient's general function ( $\mathrm{GAF}, \mathrm{r}=$
$0.64, \mathrm{p}<0.05)$, relative's distress $(\mathrm{K} 6, \mathrm{r}=-0.61, \mathrm{p}<0.05)$. For divergent validity, the FAS-SR was not correlated with the BIS II.

\section{DISCUSSION}

We translated the FAS-SR, a representative scale for assessing family accommodation in obsessive-compulsive disorder, into Korean and examined its psychometric properties. The Korean version of FAS-SR showed excellent reliability and acceptable validity and it can be easily completed by relatives at the outpatient clinic setting. As far as our knowledge, this is the first study investigates both OCD patient and their family members from a family accommodation aspect.

Regarding reliability, Korean version of the FAS-SR showed excellent internal consistency (Chronbach's alpha $=0.91$ ). The original version (Chronbach's alpha $=0.90$ ) and the Hindi version (Chronbach's alpha $=0.93)^{22}$ were similar to ours, whereas the Japanese version was lower $(0.88){ }^{21}$ Further, the Korean version's Spearman-Brown coefficient was higher than Hindi versions (Spearman-Brown coefficient $=0.75$, Guttmann's splithalf coefficient $=0.71)^{22}$ indicating that the split-half reliability of Korean version of the FAS-SR was acceptable. The ICC for each of the 19 items of the scale was higher than that of the Jap- 
Table 3. Descriptive statistics and Pearson correlations between the Korean version of the FAS-SR and study variables

\begin{tabular}{|c|c|c|}
\hline & Mean (SD) & FAS-SR \\
\hline \multicolumn{3}{|l|}{ Patient rated $(\mathrm{N}=42)$} \\
\hline YBOCS & $21.25(6.67)$ & $0.64^{*}$ \\
\hline K6 & $16.32(6.54)$ & -0.21 \\
\hline GAF & $60.53(10.34)$ & $-0.53^{*}$ \\
\hline YBOCS (obsession) & $11.07(4.41)$ & $0.67^{*}$ \\
\hline YBOCS (compulsion) & $10.10(3.65)$ & $0.50^{*}$ \\
\hline \multicolumn{3}{|l|}{ Relative rated $(\mathrm{N}=42)$} \\
\hline YBOCS (compulsion) & $11.20(3.45)$ & $0.50^{*}$ \\
\hline K6 & $23.55(3.90)$ & $-0.61^{*}$ \\
\hline FAD & $29.93(4.27)$ & -0.08 \\
\hline BIS II & $45.54(9.17)$ & -0.10 \\
\hline \multicolumn{3}{|c|}{$\begin{array}{l}{ }^{*} \mathrm{p}<0.05 \text {. FAS-SR, the Family Accommodation Scale-Self-Rated } \\
\text { version; YBOCS, Yale-Brown Obsessive Compulsive Scale; K6, } \\
\text { Kessler Psychological Distress Scale; GAF, Global Assessment of } \\
\text { Functioning; FAD, Family Assessment Device; BIS II, Barratt im- } \\
\text { pulsivity scale II; SD, standard deviation }\end{array}$} \\
\hline
\end{tabular}

anese version ( $\mathrm{ICC}=0.85, \mathrm{p}<0.01$ ). Above results support that Korean version of the FAS-SR constitute a reliable measure for consistent symptoms.

The Korean version of FAS-SR was significantly correlated with clinical factors previously known to be related to FA, such as with relative-rated psychological distress, patients rated OC symptom severity and general functioning, indicates good convergent validity. However, contrary to our expectation, there was no correlation between the Korean version of FAS and the relative-rated FAD. Validation studies in Japan and India, the FAS-SR was significantly associated with relative-rated family function. ${ }^{16,21,22}$ This discrepancy might come from that the composition of the relatives participating at the study varies among studies. In our study, the proportion of parents among relatives was $79.06 \%$, which is higher than that of the Japan $(48.8 \%){ }^{21}$ India (31.7\%), ${ }^{22}$ and United states (37\%). ${ }^{16}$ Parents tend to rate their families as more healthy than other family members with FAD.

The most common types of family accommodation in our study were item 13 ("I stopped doing things that could trigger the patient's OCD" [80.9\%]); and item 15 ("I avoided talking about OCD triggers" [78.6\%]). For a Japanese study, 21 the most common type of family accommodation was item 12 ("I avoided talking about OCD triggers" [63.4\%]), whereas in the original study it was item 1 ("I reassured patient that there were no grounds for OCD concern" [63.4\%]). These results demonstrate that in east Asia countries, the relatives of OCD patients usually modified their behavior or routine; by contrast, in the American study, they usually provided reassurance and participated in patients' compulsions. When implementing fam- ily-based Exposure and Response Prevention (ERP) in Korean OCD patients, reducing the tendency of relatives to modify their behavior to avoid symptom triggering might help to achieve good therapeutic effects.

A limitation of the present study is its relatively small sample size ( $78.57 \%$ of relatives were parents), which may limit the power of the statistical analyses and the generalizability of the results. Second, potential for sample bias should be considered, as some of the patients were under-control with treatment, whereas others were acutely ill states. Third, FAS-IR, the gold standard, was not used to confirm convergent validity. Therefore, the clinical utility of the Korean version of the FAS-SR should be further evaluated in more strictly standardized settings and assessment tool.

The results of this study are meaningful because we introduced a tool to assess family accommodation in OCD patients in Korea for the first time. The Korean version of the FAS-SR is useful as a time-efficient and cost-effective tool.

\section{Availability of Data and Material}

The datasets generated or analyzed during the study are available from the corresponding author on reasonable request.

\section{Conflicts of Interest}

Chan-Hyung Kim, a contributing editor of the Psychiatry Investigation, was not involved in the editorial evaluation or decision to publish this article. All remaining authors have declared no conflicts of interest.

\section{Author Contributions}

Conceptualization: Chan-Hyung Kim, Se Joo Kim. Data curation: Jhin Goo Chang. Formal analysis: Jhin Goo Chang. Investigation: all authors. Methodology: all authors. Supervision: Chan-Hyung Kim. Validation: Hye Min Lee. Visualization: Hye Min Lee. Writing_original draft: Jhin Goo Chang. Writing—review \& editing: all authors.

\section{ORCID iDs}

$\begin{array}{ll}\text { Jhin Goo Chang } & \text { https://orcid.org/0000-0003-3024-4893 } \\ \text { Hye Min Lee } & \text { https://orcid.org/0000-0002-2766-7740 } \\ \text { Se Joo Kim } & \text { https://orcid.org/0000-0002-5438-8210 }\end{array}$

Chan-Hyung Kim https://orcid.org/0000-0001-8419-3759

\section{Funding Statement \\ None}

\section{REFERENCES}

1. American Psychiatric Association. The Diagnostic and Statistical Manual of Mental Disorders: DSM-5. Washington, D.C.: American Psychiatric Association; 2013.

2. Crino R, Slade T, Andrews G. The changing prevalence and severity of obsessive-compulsive disorder criteria from DSM-III to DSM-IV. Am J Psychiatry 2005;162:876-882.

3. McEvoy PM, Grove R, Slade T. Epidemiology of anxiety disorders in the Australian general population: findings of the 2007 Australian National Survey of Mental Health and Wellbeing. Aust N Z J Psychiatry 2011;45:957-967.

4. Lack CW, Storch EA, Keeley ML, Geffken GR, Ricketts ED, Murphy TK, et al. Quality of life in children and adolescents with obsessive-compulsive disorder: base rates, parent-child agreement, and clinical correlates. 
Soc Psychiatry Psychiatr Epidemiol 2009;44:935-942.

5. Kugler BB, Lewin AB, Phares V, Geffken GR, Murphy TK, Storch EA. Quality of life in obsessive-compulsive disorder: the role of mediating variables. Psychiatry Res 2013;206:43-49.

6. Lack CW. Obsessive-compulsive disorder: evidence-based treatments and future directions for research. World J Psychiatry 2012;2:86-90.

7. Amir N, Freshman M, Foa EB. Family distress and involvement in relatives of obsessive-compulsive disorder patients. J Anxiety Disord 2000; 14:209-217.

8. Markarian Y, Larson MJ, Aldea MA, Baldwin SA, Good D, Berkeljon A, et al. Multiple pathways to functional impairment in obsessive-compulsive disorder. Clin Psychol Rev 2010;30:78-88.

9. Cooper M. Obsessive-compulsive disorder: effects on family members. Am J Orthopsychiatry 1996;66:296-304.

10. Stewart SE, Hu YP, Hezel DM, Proujansky R, Lamstein A, Walsh C, et al. Development and psychometric properties of the OCD Family Functioning (OFF) Scale. J Fam Psychol 2011;25:434-443.

11. Calvocoressi L, Mazure CM, Kasl SV, Skolnick J, Fisk D, Vegso SJ, et al. Family accommodation of obsessive-compulsive symptoms: instrument development and assessment of family behavior. J Nerv Ment Dis 1999; 187:636-642.

12. Calvocoressi L, Lewis B, Harris M, Trufan SJ, Goodman WK, McDougle CJ, et al. Family accommodation in obsessive-compulsive disorder. Am J Psychiatry 1995;152:441-443.

13. Wu MS, McGuire JF, Martino C, Phares V, Selles RR, Storch EA. A meta-analysis of family accommodation and OCD symptom severity. Clin Psychol Rev 2016;45:34-44.

14. Albert U, Baffa A, Maina G. Family accommodation in adult obsessivecompulsive disorder: clinical perspectives. Psychol Res Behav Manag 2017;10:293-304.

15. Storch EA, Bjorgvinsson T, Riemann B, Lewin AB, Morales MJ, Murphy TK. Factors associated with poor response in cognitive-behavioral therapy for pediatric obsessive-compulsive disorder. Bull Menninger Clin 2010;74:167-185.

16. Pinto A, Van Noppen B, Calvocoressi L. Development and preliminary psychometric evaluation of a self-rated version of the Family Accommodation Scale for Obsessive-Compulsive Disorder. J Obsessive Compuls Relat Disord 2013;2:457-465.

17. Stewart SE, Beresin C, Haddad S, Egan Stack D, Fama J, Jenike M. Predictors of family accommodation in obsessive-compulsive disorder. Ann Clin Psychiatry 2008;20:65-70.

18. Albert U, Bogetto F, Maina G, Saracco P, Brunatto C, Mataix-Cols D. Family accommodation in obsessive-compulsive disorder: relation to symptom dimensions, clinical and family characteristics. Psychiatry
Res 2010;179:204-211.

19. Flessner CA, Freeman JB, Sapyta J, Garcia A, Franklin ME, March JS, et al. Predictors of parental accommodation in pediatric obsessive-compulsive disorder: findings from the Pediatric Obsessive-Compulsive Disorder Treatment Study (POTS) trial. J Am Acad Child Adolesc Psychiatry 2011;50:716-725.

20. Gomes JB, Van Noppen B, Pato M, Braga DT, Meyer E, Bortoncello CF et al. Patient and family factors associated with family accommodation in obsessive-compulsive disorder. Psychiatry Clin Neurosci 2014;68: 621-630.

21. Kobayashi Y, Matsunaga H, Nakao T, Kudo Y, Sakakibara E, Kanie A, et al. The Japanese version of the Family Accommodation Scale for Obsessive-Compulsive Disorder: psychometric properties and clinical correlates. J Obsessive-Compulsive and Related Disorders 2017;15:27-33.

22. Mahapatra A, Gupta R, Patnaik KP, Pattanaik RD, Khandelwal SK. Examining the psychometric properties of the Hindi version of Family Accommodation Scale-Self-Report (FAS-SR). Asian J Psychiatr 2017; 29:166-171.

23. Wu MS, Lewin AB, Murphy TK, Geffken GR, Storch EA. Phenomenological considerations of family accommodation: related clinical characteristics and family factors in pediatric obsessive-compulsive disorder. J Obsessive Compuls Relat Disord 2014;3:228-235.

24. Epstein NB, Baldwin LM, Bishop DS. The McMaster family assessment device. J Marital Fam Ther 1983;9:171-180.

25. Kim SJ. Effect of an integrated therapeutic family management program on the family functioning of schizophrenic families [master's thesis]. [Seoul]: Yonsei University; 1997.

26. Goodman WK, Price LH, Rasmussen SA, Mazure C, Fleischmann RL, Hill CL, et al. The Yale-Brown Obsessive Compulsive Scale. I. Development, use, and reliability. Arch Gen Psychiatry 1989;46:1006-1011.

27. Seol SH, Kwon JS, Shin MS. Korean self-report version of the YaleBrown Obsessive-Compulsive Scale: factor structure, reliability, and validity. Psychiatry Investig 2013;10:17-25.

28. Kessler RC, Andrews G, Colpe LJ, Hiripi E, Mroczek DK, Normand SL, et al. Short screening scales to monitor population prevalences and trends in non-specific psychological distress. Psychological Medicine 2002;32:959-976.

29. Kim YS. Validation of the Korean versions of K-10 and K6 among lowincome individuals. Ment Health Soc Work 2011;37:65-88.

30. Barratt ES. Factor analysis of some psychometric measures of impulsiveness and anxiety. Psychol Rep 1965;16:547-554.

31. Heo SY, Oh JY, Kim JH. The Korean version of the Barratt Impulsiveness Scale, 11th version: its reliability and validity. Korean J Psychol Gen 2012;31:769-782. 